P167 (continued)

diabetes participating in the National Diabetes Prevention Program (NDPP). NDPPs were delivered in 12 Georgia counties (7 metropolitan; 5 nonmetropolitan) by Cooperative Extension. Participants were asked to complete two 24-hour recalls, 1 weekday and 1 weekend day, using ASA24 , without individual instruction.

Measurable Outcome/Analysis: Number and percentage of participants who completed $>1$ ASA-24s and mean + standard deviation Calorie, carbohydrate, protein, and fat intakes were calculated.

Results: Of the 86 participants asked to complete 2 ASA$24 \mathrm{~s}, 54(63 \%)$ completed $>1$ recall. Forty-eight $(56 \%)$ participants completed 1 weekday; 27 (31\%) completed 1 weekend day; and 31 (36\%) completed >2 days, with 20 (23\%) completing 1 weekday and 1 weekend day as instructed. Mean reported Calorie intake was 1,691+1,088 kcal (range, $128-7444 \mathrm{kcal})$. Mean carbohydrate, protein, and fat intakes reported were $180+109 \mathrm{~g}$ (range, 10-688 g), 77+47 g (range, 2-233 g), and 75+60 (range, 10-418 g), respectively. Of those who completed $>1$ recall, $83 \%$ were female and had at least some college education, with $100 \%$ being high school graduates and $48 \%$ college graduates.

Conclusions: While a majority (63\%) of participants completed $>1$ ASA-24 recall, $<25 \%$ completed 1 weekday and 1 weekend day as instructed. While mean nutrient intakes were reasonable, standard deviations indicate further instruction may be needed. Future analyses will assess other factors influencing feasibility.

Funding: University of Georgia Presidential Interdisciplinary Seed Grant Program.

\section{P168 Student Vegetable Sensory Perception Questionnaire Responses Associated with School Lunch Vegetable Consumption}

Nader Hamdi, BS, University of Illinois at UrbanaChampaign; Brenna Ellison, PhD, University of Illinois at Urbana-Champaign; Jennifer McCaffrey, $P h D, M P H, R D$, University of Illinois at Urbana-Champaign; Jessica Metcalfe, $P h D, M P H$, University of Illinois at UrbanaChampaign; Melissa Pflugh Prescott, PhD, RDN, mpp22@illinois.edu, University of Illinois at UrbanaChampaign, 905 S Goodwin Ave, Urbana, IL 61801

Background: Children's willingness to try (WTT) foods is positively associated with dietary quality. Sensory characteristics of foods are likely to contribute to children's WTT and dietary intake, but there is little research investigating how sensory characteristics inform vegetable consumption in real-world settings.

Objective: To investigate the relationship between students' vegetable sensory perception questionnaire responses and vegetable consumption during school lunch.

Study Design, Setting, Participants: This repeated cross-sectional study collected data at 3 rural Illinois schools over 3 months ( 3 dates at 2 schools, 2 dates at 1 school) when broccoli or peas were served. Schools participated in the National School Lunch Program and had students in grades K-8.
Measurable Outcome/Analysis: Vegetable consumption was measured by individual direct weighing of waste remaining from standardized vegetable portions. Questionnaire data used a 3-point scale, adapted from USDA Try-Day Taste-Testing Ballots, to assess if students tried the vegetable and WTT vegetable again, and allowed students to rate the vegetable's visual appeal and taste. Descriptive statistics were used to characterize the study sample. Linear regression analyses (adjusted for grade, sex, and percent entrée consumption) were used to examine the association between students' questionnaire responses and school lunch percent vegetable consumption.

Results: Participants were $51 \%$ female and $49 \%$ male ( $n=317$ students, average of $n=40$ per month per school). Responses to vegetable taste and visual appeal questions were significant predictors of percent vegetable consumption, such that students who responded positively to the questions consumed 17.1 and 17.8 percentage points more vegetables than those who responded neutrally ( $\beta=17.1$ and 17.8 , respectively, $P<.001$ ). WTT responses significantly predicted vegetable consumption, with students who responded positively consuming 15.0 percentage points more than those who responded neutrally $(\beta=15.0, P<.001)$.

Conclusions: Students' vegetable sensory perception questionnaire responses are significant predictors of school lunch vegetable consumption. Subsequently, practitioners should consider improving the visual appeal and taste of school meals, and researchers should incorporate sensory perception measures when evaluating school meal interventions.

Funding: NIFA.

\section{Written Oral and Social Media Communication}

\section{P169 Impact Comparison of a Poverty Simulation On High School and College Students' Understanding of and Sensitivity Toward Economic Hardship}

Kenzie Krieger, Southern Illinois University Edwardsville; Kennedy Profaizer, Southern Illinois University Edwardsville; Jennifer L. Zuercher, PhD, RD, LD, jzuerch@siue.edu, Southern Illinois University Edwardsville, 6 Hairpin Dr, Edwardsville, IL, 62026

Background: For those who have not experienced or been exposed to poverty, its impact can be challenging to comprehend. Providing opportunities that expose college students to these realities can enhance their ability to empathize with future patients and clients. For youth, such opportunities may also expand their familiarity with potential careers and service opportunities related to working with the poor.

Objective: To evaluate and compare the impact of the Community Action Poverty Simulation (CAPS) on perceptions of and sensitivity toward poverty among both high school and college students.

Study Design, Setting, Participants: High school and college students took part in separate simulations in which 